\begin{tabular}{ll}
\hline TOBA (Journal of Tourism, Hospitality and Destination) \\
journal.literasisains.id/index.php/TOBA \\
ISSN Media Elektronik 2828-4100 \\
Vol. 1 No. 1 (Februari 2022) 30-33 \\
DOI: https://doi.org/10.55123/toba.v1i1.136
\end{tabular}

\title{
Aksesibilitas, Atraksi dan Fasilitas Pada Daya Tarik Wisata Pacu Jawi, Tanah Datar, Sumatera Barat.
}

\author{
Ulfah Azzahra Harahap ${ }^{1}$, Cipta Endyana ${ }^{2}$, Alexander M.A.Khan ${ }^{3}$ \\ Sekolah Pascasarjana Universitas Padjadjaran ${ }^{1}$ \\ Fakultas Geologi, Universitas Padjadjaran ${ }^{2}$ \\ Fakultas Kelautan dan Ilmu Perikanan, Universitas Padjadjaran ${ }^{3}$ \\ e-mail: ulfah19002@mail.unpad.ac.id
}

\begin{abstract}
ABSTRAK
Salah satu daerah di Indonesia yang memiliki banyak unsur budaya adalah Kabupaten Tanah Datar di Sumatera Barat. Tanah Datar memiliki berbagai macam wisata budaya, Istana Basa Pagaruyung yang merupakan Kerajaan Pagaruyung misalnya, ada pula Tradisi Budaya Balap Kerbau atau Sapi yang biasa di sebut Pacu Jawi. Tradisi Minangkabau yang menggunakan sapi atau kerbau di pacu bersama dengan maksud mensyukuri rezeki dan mengharapkan keberkahan. Atraksi ini dilakukan di tanah berlumpur atau lahan sawah yang luas dan dilakukan pada saat musim panen. Kabupaten Tanah Datar memiliki berbagai macam daya Tarik wisata, terutama yang menjadi ikon pada Kabupaten Tanah Datar adalah Pacu Jawi, dimana atraksi ini sangat di gemari oleh banyak kalangan dan wisatawan. Terlebih dari pihak fotografi yang menilai bahwa "belum bisa di bilang sebagai fotografer apabila tidak lulus memotret atraksi Pacu Jawi". Pacu Jawi merupakan atraksi dengan memiliki arti rasa syukur. Akesesbilitas, Fasilitas, dan Atraksi pada Pacu Jawi ini sudah termasuk kategori baik dikarenakan semua sudah terkelola dengan baik. Metode Penelitian ini menggunakan data primer dan sekunder dimana data primer di dapatkan dari hasil wawancara dan sekunder di dapatkan dari beberapa artikel dan jurnal yang sudah tervalidasi.
\end{abstract}

Kata kunci :

Pacu Jawi, Atraksi Aksesbilitas dan Fasilitas, Tradisi

\section{ABSTRACT}

One of the areas in Indonesia that has many cultural elements is Tanah Datar Regency in West Sumatra. Tanah Datar has a variety of cultural attractions, Basa Pagaruyung Palace which is pagaruyung kingdom for example, there is also a Kerbai or Sapi Racing Cultural Tradition commonly called Pacu Jawi. Minangkabau tradition that uses cows or buffaloes in the pacu Bersama with the intention of being grateful for sustenance and expecting blessings. This attraction is done in muddy land or large rice fields and is done during the harvest season. Tanah Datar Regency has a variety of tourist attractions, especially the iconic one in Tanah Datar Regency is Pacu Jawi, where this attraction is very popular with many circles and tourists. Especially from the photography side who judged that "can not be said as a photographer if not passed photographing the attraction Pacu Jawi". Pacu Jawi is an attraction with the meaning of gratitude. Accessibility, Facilities, and Attractions in Pacu Jawi is included in the good category because everything is well managed. This research method uses primary and secondary data where the primary data obtained from the interview results and secondary is obtained from several articles and journals that have been validated.

Keywords :

Pacu Jawi; Attraction Accesibilty Amenity; Tradition

\section{A. PENDAhuluan}

Indonesia kaya akan budaya yang dapat menjadikan nama Indonesia di kenal oleh manca negara. Budaya yang ada terkadang menjadi suatu keuntungan positif bagi masyarakat yang mempunyai kultur budaya tersebut.

Suatu daya tarik wisata ialah bagian yang sangat penting bagi perkembangan sebuah daerah yang memiliki berbagai potensi wisata di dalamnya. Daya tarik wisata yang di kelola dengan baik maka dapat di nilai mampu mengembangkan suatu nama daerah di mata orang daerah maupun dari luar daerah tersebut. Menurut UU 10 Tahun 2009 tentang Kepariwisataan, Daya Tarik Wisata adalah segala sesuatu yang memiliki keunikan, keindahan, dan nilai yang berupa keanekaragaman kekayaan alam, budaya, dan hasil buatan manusia yang menjadi sasaran atau tujuan kunjungan wisatawan.

Daya tarik wisata dapat di kategorikan dengan berbagai macam jenis wisata, mulai dari wisata buatan, wisata alam, wisata budaya, dan lain sebagainya. Pada penelitian ini, Penulis berkonsen pada wisata budaya.

Wisata budaya merupakan wisata yang sudah di gemari oleh berbagai kalangan sejak dulu. Indonesia sangat kaya akan budaya, oleh karena itu sangat banyak pula daerah yang mulai mengembangkan dan tetap menjaga budaya yang sudah ada dari turun temurun. Budaya harus di jaga agar tidak pudar dan hilang, oleh sebab itu generasi baru harus di perkenalkan dengan budaya agar tetap mengenali dan tetap melaksanakan kewajiban pada budaya yang sudah dilakukan secara turun temurun. Indonesia adalah negara yang sangat kaya 
dengan budaya. Oleh sebab itu, sangat banyak budaya Indonesia yang dapat dikenal secara luas oleh wisatawan lokal maupun wisatawan asing.

Wisata budaya merupakan wisata yang memiliki unsur - unsur sejarah, atraksi, tradisi, kerajinan tangan, music dan kesenian, agama, dan lain sebagainya. Mill (2000: 12) berpendapat bahwa daya Tarik utama suatu objek wisata untuk di kunjungi adalah atraksi wisata. Namun, pada pengembangan suatu daya Tarik wisata dengan berbasis atraksi akan lebih baik lagi apabila di dukung oleh kompenen akesesibilitas dan fasilitas, dengan adanya askesbilitas maka para pengunjung wisata akan lebih di permudah dalam menjangkau suatu daya Tarik wisata tersebut. Aksesibilitas menurut Soekadijo pada tahun 2003, dengan tersedianya sarana yang membuat pengunjung memiliki kemudahan untuk menjangkau sebuah destinasi wisata,dalam hal ini tersedianya sarana transportasi menuju destinasi wisata dan jarak destinasi wisata yang terjangkau menjadi hal yang penting. Fasilitas (Ancillary) adalah sarana penunjang tambahan seperti money changer, pos keamanan, ATM, dan petugas yang ramah (Sunaryo, 2013).

Salah satu daerah di Indonesia yang memiliki banyak unsur budaya adalah Kabupaten Tanah Datar yang terletak di provinsi Sumatera Barat. Kabupaten Tanah Datar adalah salah satu dari 19 Kabupaten ataupun Kota di Provinsi Sumatera Barat, dengan luas wilayahnya yang hanya mencapai $133.600 \mathrm{Ha}$, Tanah Datar menjadi Kota terkecil di Sumatera Barat. Kabupaten Tanah Datar merupakan salah satu destinasi yang di gemari oleh berbagai masyarakat lokal atau pun wisatawan lokal. Tidak jarang pula wisatawan luar kota atau bahkan manca negara juga berkunjung ke Tanah Datar apa bila sedang berada di Provinsi Sumatera Barat, dengan berbagai atraksi dan keindahan alam bahkan budaya yang sangat banyak maka daerah ini memberikan daya Tarik tersendiri bagi masyarakat luar maupun dalam daerah.

Tanah Datar memiliki berbagai macam wisata budaya, seperti Istana Basa Pagaruyung yang merupakan situs warisan dan peninggalan Kerajaan Pagaruyung misalnya, ada pula Tradisi Budaya Balap Kerbau atau Sapi yang biasa di sebut Pacu Jawi. Tradisi Minangkabau yang menggunakan sapi atau kerbau di pacu secara bersamaan, dengan maksud mensyukuri rezeki dan mengharapkan keberkahan. Atraksi ini dilakukan di tanah berlumpur atau lahan sawah yang luas dan dilakukan pada saat musim panen. Pacu Jawi di kontrol oleh seorang pemuda yang sudah berpengalaman menguasai sapi atau kerbau yang akan dipacu atau disebut juga dengan joki. Pacu Jawi berasal dari Kecamatan Pariangan Kabupaten Tanah Datar, namun sekarang sudah banyak dilakukan di berbagai daerah di Sumatera Barat, dimana tradisi Pacu Jawi ini di lakukan di setiap hari sabtu dalam waktu 5 minggu. Di setiap pergantian 5 minggu maka pacu jawi dilaksanakan di lain tempat atau biasa di katakan dengan perpindahan Nagari. Pada minggu ke 5 akan diadakannya acara penutupan atau biasa disebut dengan Jawi Pasuntiang dengan isi acara arak arakkan beberapa kerbau atau sapi (jawi) yang akan turut serta pada acara tersebut dan Jawi tersebut di hias sedemikian rupa dan dipakaikan
Suntiang (Mahkota kebanggaan perempuan Minang) seperti hiasan kepala dan di arak keliling kampung, lalu arak arakan tersebut di pimpin oleh para ibu ibu yang membawa talam berisikan makanan makanan yang untuk di sajikan kepada para orang terkemuka serta para orang tua yang dihormati di desa tersebut.

Akses menuju ke daya Tarik wisata ini sangat mudah di karenakan terletak di tengah tengah Provinsi Sumatera Barat namun untuk para pengunjung wisata yang akan mendatangi daerah ini harus menggunakan kendaraan pribadi. Untuk fasilitas penginapan atau hotel sudah tersedia namun belum banyak dan masih dikelola oleh masyarakat sekitar, tetapi untuk system informasi, pemandu wisata sudah tersedia namun belum banyak juga, pemandu wisata biasa di dapatkan dari travel agen atau pun bisa melalui warga sekitar yang siap sedia membantu untuk memandu wisata. fasilitas parkir kendaraan tersedia apa bila kurangnya fasilitas parkir warga juga dengan suka rela akan memberikan lahan depan rumah nya untuk dijadikan lahan parkir. Artinya pengelolaan daya Tarik wisata Tanah Datar sudah terkomponen dengan baik

Pengembangan suatu objek wisata dengan basis atraksi yang layak harus di dukung pula oleh komponen akesisbilitas yang memberikan kemudahan kepada pengunjung untuk menjangkau suatu objek wisata sementara fasilitas dapat memenuhi kebutuhan pengunjungan selama wisatawan menikmati atraksi di suatu daya Tarik wisata yang di pilihnya.

Tujuan pada penelitian ini ialah peneliti akan menilai bagaimana aksesibilitas, fasilitas, dan atraksi pada daya Tarik pacu jawi di Tanah Datar, Sumatera Barat.

Berikut ini ada tiga kompenen yang utama pada produk pariwisata yang di kemukakan oleh berbagai pendapat yang meliputi komponen atraksi, aksesibilitas dan fasilitas yang terdapat dalam suatu objek wisata.

Suwantoro (2000: 18-19) menegaskan bahwa atraksi di bagi ke dalam dua golongan, yaitu atraksi alam dan atraksi buatan manusia. Atraksi alam adalah daya Tarik wisata yang melekat pada keindahan dan keunikan alam dari pencipta yang terdiri dari keindahan alam, iklim, pemandangan, fauna, dan flora yang jarang dilihat atau langka, hutan, dan sumber kesehatan seperti sumber air panas belerang, dan mandi lumpur. Sedangkan atraksi buatan manusia adalah segala sesuatu yang menjadi daya Tarik wisata yang sengaja di ciptakan atau di buat oleh manusia, misalnya monument, candi, museum art atau kesenian, festival, pesta ritual, upacara perkawinan tradisional dan sebagainya.

Objek dan daya Tarik wisata memiliki komponen yang sangat menentukan, maka harus di bentuk dan di kembangkan atau di kelola secara professional sehingga dapat menarik pengunjung. Umumnya daya Tarik suatu daya Tarik wisata berdasarkan pada:

1. Adanya sumber daya yang dapat menimbulkan rasa senang, indah, nyaman, dan bersih.

2. Adanya aksesibilitas yang tinggi untuk dapat mengunjunginya.

3. Adanya ciri khusus atau spesifikasi yang bersifat langka. 
4. Sarana atau prasarana penunjang untuk melayani para wisatawan yang berkunjung

5. Daya Tarik wisata alam mempunyai daya Tarik yang tinggi karena keindahan alam pegunungan, sungai, pantai, pasir, dan hutan.

Kegiatan dan objek yang merupakan atraksi itu sendiri harus dalam keadaan yang baik;

1. Atraksi wisata harus di sajikan di hadapan wisatawan maka cara penyajiannya harus tepat,

2. Atraksi wisata adalah yerminal dari suatu mobilitas spasial suatu perjalanan. Oleh karena itu harus memenuhi semua determinan mobilitas spasial yaitu akomodoasi, transportasi, dan promosi serta pemasaran,

3. Keadaan di tempat atraksi harus dapat menahan wisawatan cukup lama.

\section{B. METODE PENELITIAN}

Penelitian ini merupakan penelitian yang menggunakan data primer dan sekunder. Data Primer pada penelitian ini di dapat dari hasil wawancara wisatawan yang pernah berkunjung kesana dan pemuda minangkabau. Sementara data sekunder pada penelitian ini menggunakan data yang di dapatkan dari berbagai artikel dan jurnal yang telah tervalidasi datanya.

Penelitian ini mengambil lokasi di Kabupaten Tanah Datar, Sumatera Barat. Objek penelitian ini adalah Atraksi Pacu Jawi yang ada di Tanah Datar, Sumatera Barat. berikut:

Operasional dalam penelitian ini adalah sebagai

1. Atraksi menurut Roger and Slinn (1998: 12) menyatakan bahwa atraksi atau daya Tarik adalah segala sesuatu yang terdapat di objek wisata yang menjadi daya Tarik hingga wisatawan yang mengunjungi tempat tersebut dengan indikator panoranama keindahan keunikan dan serta kebersihan dan kesenian objek wisata.

2. Aksesbilitas menurut Suwantoro (2000) adalah suatu sarana yang menghubungkan pengunjung dengan suatu objek wisata yang berbentuk akses informasi dan alat transportasi dengan indicator transportasi, kemudahan lokasi, kenyamanan dalam perjalanan dan kondisi jalan.

3. Fasilitas, menurut Spillane (2000: 23) mengatakan bahwa suatu fasilitas fisik (physical facility) merupakan sarana yang disediakan oleh pengelola objek wisata untuk memberikan pelayanan ataupun kesempatan pada wisatawan yang menikmatinya dengan indicator fasilitas penginapan, tempat parkir, tempat belanja, ruang pengelola, kamar mandi dan toilet.

\section{HASIL DAN PEMBAHASAN}

Atraksi, aksesibilitas dan amenitas merupakan komponen penting dalam pengembangan objek wisata karena daya tarik suatu destinasi wisata terletak pada ketiga komponen tersebut selain penunjang. Suatu tempat yang dapat dikembangkan menjadi suatu destinasi pariwisata perlu memenuhi 4 (empat) komponen pariwisata yang disebut 4A yaitu atraksi, aksesibilitas, amenitas dan penunjang (Andrianto \& Sugiama, 2016)

Tanah Datar mempunyai atraksi budaya yaitu Pacu Jawi yang dilakukan umumnya di Kawasan persawahan yang luas atau tanah yang berlumpur. Aksesbilitas, Fasilitas, dan Atraksi pada daerah Tanah Datar ini;

1. Aksesbilitas pada daya Tarik wisata Pacu Jawi, Kabupaten Tanah Datar, Sumatera Barat termasuk kategori Baik, dikarenakan akses menuju ke daerah Tanah Datar jalan sudah teraspal dan mudah dilalui oleh kendaraan pribadi ataupun bus besar, namun apabila bus terparkir di pinggir jalan akan mengakibatkan kemacetan, untuk bus bisa di parkirkan di lahan besar miliki warga sekitar. Adanya perpindahan lokasi di setiap 5 minggunya pada pengadaan acara pacu jawi, namun akses menuju lokasi ini masih bisa di jangkau dan memiliki lahan untuk parkir. Beberapa pihak travel yang ada di Sumatera Barat juga sering menawarkan perjalanan menuju Tanah Datar dikarenakan banyaknya daya Tarik wisata yang ada disana. Jarak menuju daya Tarik wisata Pacu Jawi Tanah Datar termasuk mudah, dikarenakan posisi daerah Tanah Datar sendiri adalah Kabupaten yang berada di tengah tengah Sumatera Barat. Jarak yang dilalui apabila dari Bandara Internasional Minangkabau menuju Ibukota Kabupaten Tanah Datar yaitu Batusangkar sekitar $101 \mathrm{~km}$ dapat ditempuh dalam waktu 3jam, dari Kota Padang Panjang menuju Batusangkar 28km dapat ditempuh dalam waktu kurang lebih 45 menit, dari Kota Bukit Tinggi menuju Batusangkar 40km memakan waktu 1 jam 30 menit, dan Pakumbuh ke Batusangkar $50 \mathrm{~km}$ dapat ditempuh dalam waktu 1 jam 45 menit.

2. Atraksi yang dapat di nikmati di Kabupaten Tanah Datar antara lain, Panorama Tabek Patah Istano Basa Pagaruyung yang di dalamnya terdapat museum Kerajaan Pagaruyung, Danau Singkarak, Air Terjun Lembah Anai, Desa Terindah di Dunia, Batu Batikam, Batu Basureh, Ustano Rajo dan lainnya. Kebanyakan atraksi yang ada di Tanah Datar adalah pesona alam, budaya, dan sejarah. Namun terkhusus atraksi yang sangat di kenal oleh banyak orang adalah atraksi Pacu Jawi.

Fasilitas, dari segi fasilitas daerah Tanah Datar khususnya pada daya Tarik Pacu Jawi ini belum begitu banyak memiliki pos keamanan, dikarenakan 
biasanya pacu jawi dilaksanakan di berbagai persawahan desa dan hampir semua warga ikut serta dalam acara tersebut. Sarana penukaran uang juga tidak terdapat di daerah ini dikarenakan wisawatan yang berkunjung kebanyakan warga sekitar ataupun wisawatan dalam negeri. Untuk fasilitas kesehatan, masyarakat selalu ikut bergotong royong dan membantu apabila seandainya terjadinya kecelakaan pada atraksi tersebut. Untuk toilet, wisatawan bisa menumpang pada rumah warga sekitar atau di Masjid terdekat.

\section{E. SIMPULAN}

Indonesia kaya akan budaya yang secara tidak langsung akan membangkitkan dan mengenalkan nama Indonesia di manca negara. Wisata budaya sangat di manfaatkan oleh beberapa pihak termasuk pihak masyarakat yang memiliki kultur budaya tersebut. Salah satu daerah yang memiliki kaya akan budaya adalah Sumatera Barat terkhusus daerah Kabupaten Tanah Datar memiliki berbagai macam daya Tarik wisata, terutama yang menjadi ikon pada Kabupaten Tanah Datar adalah Pacu Jawi, dimana atraksi ini sangat di gemari oleh banyak kalangan dan wisatawan. Terlebih dari pihak fotografi yang menilai bahwa "belum bisa di bilang sebagai fotografer apabila tidak lulus memotret atraksi Pacu Jawi”. Pacu Jawi merupakan atraksi dengan memiliki arti rasa syukur. Akesesbilitas, Fasilitas, dan Atraksi pada Pacu Jawi ini sudah termasuk kategori baik dikarenakan semua sudah terkelola dengan baik.

\section{DAFTAR PUSTAKA}

Abdulhaji, Sulfi, Ibnu SHY. (2016). Pengaruh Atraksi, Aksesibilitas dan Fasilitas Terhadao Citra Objek Wisata Danau Tolire Besar di Kota Ternate. Jurnal Penelitian Humano. Vol 7 No. 2 Edisi November

Ismail, Taufiq, Fatchur Rohman. (2019). Peran Atraksi, Aksesibilitas, Amenitas, Ancillary Pada Pengunjung Kepuasan dan Loyalitas Sikap Pengunjung Pantai Gili Ketapang. Jurnal Manajemen Teori dan Terapan. Thn 12 No.2 Agustus.

Jdih.kemenkeu.go.id. di akses pada tanggal 15 Januari 2020

https://jdih.kemenkeu.go.id/fullText/2009/10TAH UN2009UU.HTM

Mill, Robert Christie. (2000). Tourism, The International Business: Terjemahan Tri Budi Satrio. Jakarta: Penerbit Raja Grafindo.

Pemkab.tanahdatar.go.id diakses pada tanggal 27 Desember 2020

Setyanto, Ilham, Edriana Pangestuti. (2019). Pengaruh Komponen Destinasi Wisata (4A) Terhadap Kepuasan Pengunjung Pantai Gemah Tulungagung. Jurnal Administrasi Bisnis (JAB). Vol 72 No 1 Juli.

.Sunaryo, Bambang. (2013). Kebijakan Pembangunan Destinasi Pariwisata Konsep dan Aplikasinya di Indonesia. Yogyakarta: Gava Media. 